\title{
O CLIMA COMO RECURSO NA CONFERÊNCIA TÉCNICA DA ORGANIZAÇÃO METEOROLÓGICA MUNDIAL
}

\author{
MARIA Jõ̃o AlCOFORADO ${ }^{1}$
}

O clima afecta diversos aspectos das actividades humanas e pode ser considerado tanto um factor de risco como um recurso. A variabilidade do clima e as variações a longo prazo têm grande influência na disponibilidade de recursos naturais e nas sociedades humanas. Neste contexto, o clima pode ser visto como um dos mais importantes recursos naturais, que, se bem compreendido e adequadamente gerido, poderá contribuir para o desenvolvimento sustentável. O conhecimento do sistema climático tem evoluído muito rapidamente, sobretudo nas últimas décadas, devido à tomada de conciência da sua importância e a rápidos progressos tecnológicos na monitorização e na modelação do clima. Os resultados dos estudos permitirão aos diferentes sectores da sociedade lidar com os riscos relacionados com episódios climáticos extremos e beneficiar dos recursos climáticos.

Para discutir e partilhar ideias, experiências e conhecimentos, teve lugar, a 1 e 2 de Novembro de 2005, em Pequim, a Conferência Técnica sobre o tema 'Clima como Recurso', organizada pela Organização Meteorológica Mundial (OMM). Participaram estudiosos do clima, a maior parte proveniente de Institutos de Meteorologia, e também 'utilizadores', oriundos de 71 países.

Na sessão de abertura, o Secretário-Geral da OMM, M. Jarraud, salientou que o clima constitui um recurso apreciável, a preservar para as gerações vindouras. Ressaltou os dois grandes temas em discussão na conferência: a) Salientar as potencialidades da informação climática na exploração sustentável dos recursos naturais, susceptíveis de desempenhar um papel-chave na vida e no bem-estar das sociedades e b) Discutir as formas mais eficazes de transmissão da informação dos Institutos de Meteorologia e de Hidrologia para os utentes.

As conferências foram agrupadas em quatro blocos (dois por dia): a importância do clima no desenvolvimento sustentável, os problemas relacionados com a água, a dependência climática da produção de alimentos e a influência do clima no conforto, na saúde e no planeamento urbano.

1 Professora Catedrática da Universidade de Lisboa, Investigadora do Centro de Estudos Geográficos. E-mail: mjalc@fl.ul.pt 


\section{PRIMEIRA SESSÃO: 'CLIMA, DESENVOLVIMENTO SUSTENTÁVEL E ECONOMIA'2}

O presidente da Comissão de Climatologia da OMM, Y. Boodhoo, orador da conferência introdutória, frisou a importância do clima em diferentes sectores socio-económicos, tais como agricultura e pecuária, gestão da água, assim como no sector energético e no turismo. Salientou que um dos objectivos desta conferência era divulgar os 'serviços climáticos', identificando os seus potenciais utilizadores e dar a conhecer medidas apropriadas às diversas actividades, tendo em conta as previsões de variação do clima a médio prazo. No caso da saúde humana, dado como exemplo, se as previsões espacializadas das vagas de calor forem atempadamente conhecidas, de modo a desencadear sistemas de alerta, poder-se-ão esperar resultados positivos na diminuição quer da morbilidade e mortalidade associadas a esses episódios meteorológicos extremos, quer de prejuízos económicos. Por outro lado, os conhecimentos climáticos podem ser utilizados de modo inteligente para reduzir o consumo de energia. O orador reconheceu que a indústria do turismo é hoje uma das mais importantes e que depende, em larga medida, do clima. Afirmou igualmente que, com a informação climática adequada, se poderão atingir objectivos de qualidade, segurança e conforto nas cidades, dando especial atenção ao planeamento e desenho urbano. Se a génese climática de certos desastres naturais é indiscutível, a relação entre o aumento da sua frequência e as variações climáticas globais é ainda um problema em discussão.

Os três oradores, que se seguiram nesta sessão, falaram de recursos climáticos diferentes, mas com importantes consequências económicas: F. Frangialli, secretáriogeral da Organização Mundial do Turismo (OMT), Panmao Zhai ${ }^{3}$, Presidente da China Meteorological Administration (CMA) e Hatwig Dobesch, do Instituto de Meteorologia e Geodinâmica da Áustria. O primeiro considerou que o clima é um recurso-chave para todas as formas de turismo, que pressupõem actividades ao ar livre; noutras formas de turismo, o clima terá uma influencia indirecta - por exemplo na disponibilidade e qualidade da água doce. A OMM e a OMT deverão colaborar de modo a que o turismo continue a gerar benefícios socio-económicos a diversos países e proporcione experiências de qualidade aos turistas. Referiu estações de desportos de Inverno, em que a variabilidade do clima (neste caso a diminuição da queda de neve) gerou já um grave problema: as empresas não estão a investir abaixo de $2000 \mathrm{~m}$ de altitude nos Alpes. Por outro lado, a produção de neve artificial também está dependente das reservas de água. A partir deste e de outros exemplos, mostrou que a OMT considera muito importante a inclusão de informação climática e das previsões a médio e longo prazo nos projectos de desenvolvimento futuro, tal como foi focado na "Primeira Conferência sobre Variação do Clima e Turismo", que teve lugar em Djerba (Tunísia), em 2003.

Os outros dois oradores centraram-se nas energias alternativas, curiosamente quase exclusivamente na produção de energia eólica. Esta não tem custos de importação, não está dependente do aumento do preço dos combustíveis, não emite gases de estufa e é um recurso renovável. No caso da China, a produção de energia eólica aumentou de $20 \mathrm{MW}$ (em 1992) para $200 \mathrm{MW}$ em 2004; pretendem atingir-se $20 \mathrm{GW}$

2 Apenas serão contempladas as conferências que constam de um CD "Climate as Resource", distribuído no final do colóquio.

3 Refere-se apenas o orador, mesmo das conferências preparadas em colaboração. 
até 2020. Com o exemplo da Áustria, foram enumerados factores de exclusão para a localização de geradores eólicos e abordado o ponto de vista dos utilizadores e do público em geral, que concorda com a utilização deste tipo de energia alternativa, desde que não seja na sua propriedade. A esse propósito, referiu-se o síndroma NIMBY (Not In My BackYard).

\section{SEGUNDA SESSÃO: 'O CLIMA E A ÁGUA'}

A Conferência inicial foi proferida pelo japonês K. Takeuchi, que evocou a necessidade de fornecer cada vez mais informação climatológica e hidrológica à sociedade civil que, segundo ele, terá de aprender a tomar as decisões apropriadas para se proteger dos impactes dos acontecimentos meteorológicos extremos, tais como cheias e secas. Obviamente, a importância da informação climática aumenta à medida que cresce a vulnerabilidade das sociedades em relação aos extremos climáticos. Vindo de Nairobi (Climate Prediction and Application Centre), Laban A. Ogallo interrogou-se se os Institutos Meteorológicos se apercebem das necessidades do público; como aspecto positivo, referiu forums, que têm lugar desde 1998, agregando cientistas, decisores e utentes e que têm dado uma enorme contribuição para a previsão estacional, para a disseminação da informação em África e para a gestão dos riscos naturais. Também contribuem para intensificar ou iniciar o diálogo entre os estudiosos do clima e uma faixa muito larga de utilizadores. Continuando sobre o mesmo tema, Won-Tae Yun, da Korea Meteorological Administration deteve-se sobre dois principais problemas: a fragilidade de muitos modelos de previsão a longo prazo e a dificuldade da comunicação dos resultados à população, por vezes pouco instruída. J.H.Y. Katima resumiu as conclusões do relatório do IPCC de 2001, pouco relevantes, uma vez que se espera um novo relatório no início de 2007, e M.N. Ward (International Research Institute for Climate Prediction, EUA) falou sobre os serviços climáticos necessários para a gestão dos recursos em água.

\section{TERCEIRA SESSÃO: 'CLIMA E PRODUÇÃO DE ALIMENTOS'.}

A terceira sessão foi dedicada ao tema 'Clima e produção de alimentos'. Roger Stone, da Universidade de Qeensland, proferiu a conferência introdutória, tendo falado sobre 'Informação climática, previsão climática e produção de alimentos'. Iniciou a intervenção pela apresentação da variabilidade da precipitação em diversas áreas do globo, suas causas e consequências na agricultura. Mostrou, a partir de diversos exemplos, como a transmissão às populações de previsões climáticas a médio prazo e a adaptação das técnicas de cultivo podem ter resultados positivos. Fez notar que as previsões a diversas escalas temporais da variabilidade ou da variação climática poderão necessitar de medidas específicas: por exemplo, uma variabilidade da precipitação com uma frequência esperada de alguns meses terá como consequência a adaptação da data da sementeira, ao passo que uma variação climática levará à modificação do uso do solo, do tipo de culturas agrícolas, etc.

Nas sessões subsequentes, estes princípios foram ilustrados com exemplos do continente africano (por F. Karanja, Universidade de Nairobi), da África sub-sahariana (L.S. Unganai, Zimbabwe), da produção de açúcar das ilhas Fidji (J. Gawater, Sugar 
Cane Research Centre, Fidji), da Tailândia (N. Ouprasitwong, Departamento de Meteorologia tailandês), do Malawi (D. R. Kamdonyo, Serviços Meteorológicos daquele país, que referiu sobretudo o problema da gestão das secas) e da China (Chunqiang Li; Instituto de Meteorologia da província Hebei, China e Lu Houquan, do Chinese Meteorological Administration de Pequim). A comunicação de N. Ward, vindo de The Earth Institute at Columbia University, com o título 'Futuros serviços climáticos para aproveitar oportunidades e vencer desafios na agricultura' foi baseada numa reflexão sobre a gestão dos recursos e riscos para as práticas agrícolas e sobre o modo de fundir os conhecimentos ancestrais das populações com o manancial de informação climática e as previsões a médio prazo agora disponíveis.

\section{QUARTA SESSÃO: 'INFLUÊNCIA DO CLIMA NO CONFORTO, NA SAÚDE E NO PLANEAMENTO URBANO’.}

No início desta sessão, Nina. V. Kobysheva, do Observatório Geofísico de S. Petersburgo, referiu que o sucesso da climatologia aplicada depende da precisão da estimação dos recursos climáticos e fez uma súmula dos diferentes campos de aplicação dos conhecimentos climáticos. Retomou alguns tópicos já focados e referiu-se a outros temas que seriam tratados em mais pormenor nesta sessão: o clima como risco e recurso para a saúde humana e o planeamento urbano, a diversas escalas. Apresentou uma metodologia de construção de 'índices de recursos climáticos' aplicados à Rússia. Gerd Jendritzky (Serviços Meteorológicos da Alemanha) falou da potencialidade dos serviços climáticos aplicados ao sector da saúde. Referiu problemas devidos a stress térmico, radiação ultra-violeta, pólens e poluição do ar, doenças transmitidas por insectos, pela água ou pela alimentação e devidas a episódios climáticos extremos e sua variabilidade e variação temporal. Na segunda parte da sua intervenção, além de referir a importância das previsões meteorológicas e das suas consequências na população, fez a transição para as conferências subsequentes, indicando as modificações necessárias em termos de planeamento urbano e arquitectura, para reduzir o stress térmico no exterior e interior dos edifícios. Em seguida, eu própria apresentei um exemplo dos passos a seguir, desde a utilização da informação climática até à enumeração de orientações climáticas para o ordenamento urbano (na escala mesoclimática), com o objectivo de aproximação à 'cidade meteorologicamente utópica', através de selecção de estratégias adequadas. Foram dados exemplos de Lisboa. Finalmente, Xiaoyi Fang (do Beijing Meteorological Bureau) falou também das relações entre clima urbano e ordenamento a diversas escalas, dando exemplos de cidades chinesas. No caso de Pequim, foi apresentada a cidade, no seu conjunto, e também o parque olímpico, em construção, com simulações na escala microclimática.

É de notar que, na conferência sobre 'Recursos', foram muito frequentes as referências aos riscos que lhes estão associados, sobretudo no caso da gestão da água, da agricultura e da influência do tempo e do clima na saúde e em certas actividades humanas (como os seguros). O tema das variações climáticas esteve também sempre presente nas diversas discussões. Foram numerosas as sugestões para a intensificação do diálogo com as diversas comunidades de utilizadores. As principais conclusões desta conferência foram o ponto de partida de numerosas discussões da 14 . $^{\text {a }}$ reunião da Comissão de Climatologia da OMM, que se lhe seguiu, durante uma semana. 